\title{
Prevalence of the genus Cladosporium on the integument of leaf-cutting ants characterized by 454 pyrosequencing
}

\author{
A. P. M. Duarte - M. Ferro - A. Rodrigues • \\ M. Bacci Jr. • N. S. Nagamoto $\cdot$ L. C. Forti • \\ F. C. Pagnocca
}

Received: 2 February 2016/Accepted: 8 June 2016/Published online: 15 June 2016

(C) Springer International Publishing Switzerland 2016

\begin{abstract}
The relationship of attine ants with their mutualistic fungus and other microorganisms has been studied during the last two centuries. However, previous studies about the diversity of fungi in the ants' microenvironment are based mostly on culturedependent approaches, lacking a broad characterization of the fungal ant-associated community. Here, we analysed the fungal diversity found on the integument of Atta capiguara and Atta laevigata alate ants using 454 pyrosequencing. We obtained 35,453 ITS reads grouped into 99 molecular operational taxonomic units (MOTUs). Data analysis revealed that $A$. capiguara drones had the highest diversity of MOTUs. Besides the occurrence of several uncultured fungi, the
\end{abstract}

Electronic supplementary material The online version of this article (doi:10.1007/s10482-016-0724-3) contains supplementary material, which is available to authorized users.

A. P. M. Duarte $(\bowtie) \cdot$ M. Ferro · A. Rodrigues ·

M. Bacci Jr. · F. C. Pagnocca

Center for the Study of Social Insects, UNESP - São Paulo

State University, Avenida 24-A, n. 1515, Bela Vista,

Rio Claro, SP 13.506-900, Brazil

e-mail: ana.mirandaduarte@gmail.com

A. Rodrigues - M. Bacci Jr. · F. C. Pagnocca

Department of Biochemistry and Microbiology,

UNESP - São Paulo State University, Rio Claro, SP,

Brazil

N. S. Nagamoto $\cdot$ L. C. Forti

Department of Plant Protection, UNESP - São Paulo State

University, Botucatu, SP, Brazil mycobiota analysis revealed that the most abundant taxa were the Cladosporium-complex, Cryptococcus laurentii and Epicoccum sp. Taxa in the genus Cladosporium were predominant in all samples, comprising $67.9 \%$ of all reads. The remarkable presence of the genus Cladosporium on the integument of leaf-cutting ants alates from distinct ant species suggests that this fungus is favored in this microenvironment.

Keywords Next generation sequencing · ITS · Attini ants $\cdot$ Cuticle $\cdot$ Fungal consortium

\section{Introduction}

Colonies of leaf-cutting ants (genera Atta and Acromyrmex) of the tribe Attini (Formicidae) harbor a wide diversity of microorganisms. The principal member of this complex network of interactions is a basidiomycetous fungus (Agaricaceae, genus Leucoagaricus) cultured by these ants for food (Silva et al. 2003). After 50 million years of co-evolution, attine ants and their cultivated fungus are dependent on each other and therefore feature an obligatory mutualistic relationship (Mueller 2012; Schultz and Brady 2008).

Leaf-cutting ants cut large amounts of plant materials as substrate for the cultivation of the mutualistic fungus (Weber 1972) and this is why they are considered pests to agriculture crops causing severe 
economical losses. Thus, many studies have been conducted about the relationship of leaf-cutting ants with Leucoagaricus and other associated microbial symbionts in order to elucidate their ecology and assist in the search for methods to control these insects (Ortiz and Orduz 2000; Lopez and Orduz 2003; Folgarait et al. 2011).

Once a year, the reproductive caste of leaf-cutting ants, composed by alate individuals, leaves the nest to perform the mating flight. Females (gynes) carry a small portion of Leucoagaricus in their infrabuccal pocket and, after the fecundation by males (drones), each gyne tries to establish a new colony (Autuori 1941).

The study of Pagnocca et al. (2008) was the first to analyse the fungal community present in the integument of leaf-cutting gynes from Atta capiguara and Atta laevigata nests and isolated several fungal species with prevalence of the genus Cladosporium. A few years later, Duarte et al. (2014) reported the presence of potentially pathogenic black fungi, such as Exophiala and Ochroconis, in the gynes' body of the same species. Therefore, the fungi present in the integument of alate ants may be dispersed in the environment and thus compose the fungal community of the newly founded colony.

The first study aiming to evaluate the fungal diversity associated with nests of leaf-cutting ants using a culture-independent method was performed by Rodrigues et al. (2014). Using clone libraries based on the internal transcribed spacer (ITS) region, the authors analysed the fungal community in the chambers' soil and the surrounding soil of Atta sexdens rubropilosa and Atta bisphaerica nests. The authors found differences between fungal communities in nest and non-nest soils, revealing that ants may influence the mycobiota found in the soil adjacent to their nests.

Culture-independent methods, such as next generation sequencing (NGS), have been widely used in environmental studies of the mycobiome, such as soil fungi (Lim et al. 2010; Lentendu et al. 2011), mycorrhizal fungi (Lumini et al. 2010) and plantassociated fungi (Gillevet et al. 2009; Arfi et al. 2012) but not in mycobiomes found in fungal-insect interactions.

Because almost all studies on the diversity of fungi associated with leaf-cutting ants have used culturedependent approaches, here we used 454 pyrosequencing to further evaluate the mycobiota diversity on gynes and drones of the ants A. capiguara and A. laevigata. This study represents the first survey of fungal communities present on the integument of leafcutting ants using a NGS method.

\section{Methods}

Study site and sampling

One colony of A. laevigata and one colony of $A$. capiguara located at Fazenda Santana (Locality: $22^{\circ} 50.6^{\prime} \mathrm{S}$; $48^{\circ} 26.1^{\prime} \mathrm{W}$; elevation $798 \mathrm{~m}$ ), Botucatu, São Paulo State, Brazil, were monitored for several months before the mating flight season. This generally occurs once a year from September to November in São Paulo State. On the collection day (November 2012) only these two colonies released alates, thus limiting the number of colonies sampled. All ants were collected on the same day during the beginning of the mating flight, right at the moment when the alate ants appeared at the nest entrance. Ten drones and ten gynes were picked up from the A. capiguara colony and ten drones from the A. laevigata colony. Gynes of A. laevigata were not released at the moment of collection.

\section{Molecular analysis}

Each ant was immersed individually in TE buffer (Tris $1 \mathrm{M}$; EDTA $0.5 \mathrm{M}$ ) and sonicated in a Branson 1210 ultrasonic water bath for $10 \mathrm{~min}$. Due to the different sizes, one $\mathrm{mL}$ of buffer was used for drones and four $\mathrm{mL}$ for gynes. The buffer, containing fungal cells in suspension was evaporated to dryness in a Speed-Vac concentrator (Savant Instruments) and then suspended in $30 \mu \mathrm{L}$ of TE buffer. The resulting suspension was used for DNA extraction according to the CTAB protocol of Reis et al. (2015). Extracted DNA of each ant group was mixed according to the source, resulting in three samples (A. capiguara and A. laevigata drones; A. capiguara gynes).

The ITS region of the ribosomal DNA was amplified using the primers ITS1 and ITS4 (White et al. 1990). Fifteen ng of template DNA were used for a 25 $\mu \mathrm{L}$ PCR amplification reaction performed as follows: $94{ }^{\circ} \mathrm{C}$ for $5 \mathrm{~min}$, followed by 35 cycles consisting of $94{ }^{\circ} \mathrm{C}$ for $45 \mathrm{~s}, 52{ }^{\circ} \mathrm{C}$ for $30 \mathrm{~s}$ and $72{ }^{\circ} \mathrm{C}$ for $1 \mathrm{~min}$, and post elongation step at $72{ }^{\circ} \mathrm{C}$ for $7 \mathrm{~min}$. To reduce 
PCR biases, six PCR reactions were carried out for each sample and then pooled per sample group. Amplicons were analysed on a $1 \%$ agarose gel and a negative control (DNA free) was also performed. Amplicons were purified using a NucleoSpin ${ }^{\circledR}$ PCR Clean-up (Macherey-Nagel). Pyrosequencing was performed on a Genome Sequencer (GS) FLX+ platform (Roche, Switzerland) at the MACROGEN DNA Synthesis and Sequencing Facility (Seoul, Korea).

\section{Bioinformatics and data analyses}

Reads were submitted to the online program PRINSEQ (Schmieder and Edwards 2011) to examine the presence of ambiguities (Ns), quality, average size and GC content. The data have been deposited in the National Center for Biotechnology Information BioProject database, www.ncbi.nlm.nih.gov/bioproject (project ID PRJNA321130). After checking that the reads quality was higher than the 20 PHRED (Ewing and Green 1998; Ewing et al. 1998), sequences shorter than $400 \mathrm{bp}$ were removed using a local script.

The data obtained were analysed using ITScan (Ferro et al. 2014), a recent pipeline dedicated to studies on fungal diversity (available at http://evol.rc. unesp.br:8083/editor/faces/itscan/input.xhtml). Pipeline steps comprise a chimera screening, executed by the Chimera Checker program (Nilsson et al. 2010), removal of chimeric ITS sequences, sequence alignment performed in MAFFT (Katoh and Standley 2013), clustering of aligned sequences into molecular operational taxonomic units (MOTUs) using a sequence similarity of $97 \%$ (Tedersoo et al. 2010) in Mothur (Schloss et al. 2009). Singletons (MOTUs including only one read) were removed from further analysis, as recommended by Tedersoo et al. (2010), in order to improve the precision of diversity estimates.

In order to provide taxonomic affiliations, comparisons of MOTUs against the NCBI-GenBank were carried out using 1e-03 e-value parameter. The identification of the MOTUs was also manually refined by constructing phylogenetic trees including sequences from reference strains (type) available in the GenBank (neighbor-joining method) using MEGA6 (Tamura et al. 2013).

The taxonomic assignment was determined using the MycoBank (www.MycoBank.org; Robert et al. 2013). Fisher's alpha diversity index, a suitable tool for comparing samples of different sizes (Loro et al.
2012), and rarefaction curves were generated in PAST. Additionally, Sorensen and Jaccard's similarity indices were calculated to compare the communities using EstimateS 8.2.0 software (Colwell et al. 2012).

\section{Results}

A total of 142,930 reads were obtained and after filtering out short sequence reads $(<400 \mathrm{bp}), 99,281$ reads $(69.5 \%)$ were used in the ITScan pipeline. The number of reads per sample and average read length are shown in Table 1. The PHRED quality score for all samples was higher than 20 and GC content ranged from $46.8 \%$ (A. capiguara drones) to $48.1 \%$ (A. laevigata drones).

After removing chimeric sequences, 57 singletons were deleted and reads were grouped into 99 distinctive MOTUs: 51 from $A$. capiguara drones, 25 from $A$. capiguara gynes and 46 from A. laevigata drones.

Of the 99 MOTUs obtained in the study, 32 were unique to A. capiguara drones (including Cryptococcus laurentti, Cunninghamella and Periconia species), 11 were unique to A. capiguara gynes (including Trichosporon chiarellii) and 37 were unique to A. laevigata drones (including Aureobasidium and Epicoccum species). The mutualistic fungus Leucoagaricus gongylophorus was shared by drones (5 reads) and gynes (351 reads) of A. capiguara. Additionally, four MOTUs were present in all samples (Table 2). The sequence data of the ITS region are too conserved to distinguish different species in the genera Aspergillus, Cladosporium, Penicillium and Trichoderma (Balajee et al. 2007; Visagie et al. 2014; Bensch et al. 2015; Montoya et al. 2016). Therefore these MOTUs were grouped as a species complex. A complete list of the MOTUs and their distribution has been included in Online Resource 1.

According to Jaccard and Sorensen's indices, $A$. capiguara drones and A. capiguara gynes shared the highest number of fungal taxa (Jaccard: 0.24; Sorensen: 0.39). This comparison is not possible for $A$. laevigata since gynes were not obtained from this nest.

Most of the MOTUs contained 3-100 reads, however three MOTUs grouped over 1000 reads. These three MOTUs were taxonomically assigned to the Cladosporium-complex $(\mathrm{n}=24,099)$, Cryptococcus laurentii $(\mathrm{n}=2752)$, and Epicoccum sp. $(\mathrm{n}=3955)$ and made up $86.9 \%$ of the reads. Table 3 shows the most representative MOTUs in the samples. 
Table 1 Data characteristics before and after ITScan processing

\begin{tabular}{lllcc}
\hline & Raw data & & \multicolumn{2}{c}{ Treated data $^{\text {a }}$} \\
\cline { 2 - 3 } & No. of reads & $\begin{array}{l}\text { Average } \\
\text { read length }\end{array}$ & $\begin{array}{l}\text { No. of reads } \\
\text { read length }\end{array}$ \\
\hline A. capiguara drones & 44,604 & 508 & 22,953 & 519 \\
A. capiguara gynes & 74,966 & 454 & 934 & 512 \\
A. laevigata drones & 23,360 & 504 & 11,566 & 505 \\
\hline
\end{tabular}

${ }^{a}$ Reads characteristics after length filtering and removal of chimeric sequences

Table 2 Shared MOTUs for A. capiguara drones and gynes, and A. laevigata drones

\begin{tabular}{|c|c|c|c|c|c|c|c|}
\hline \multirow{2}{*}{$\begin{array}{l}\text { Best hit at NCBI } \\
\text { database }\end{array}$} & \multirow{2}{*}{$\begin{array}{l}\text { Taxonomic } \\
\text { assignment }\end{array}$} & \multirow{2}{*}{$\begin{array}{l}\text { Coverage } \\
(\%)\end{array}$} & \multirow{2}{*}{$\begin{array}{l}\text { Similarity } \\
(\%)\end{array}$} & \multirow{2}{*}{$\begin{array}{l}\text { Accession } \\
\text { no. }\end{array}$} & \multicolumn{3}{|l|}{ No. of reads } \\
\hline & & & & & AC drones & AC gynes & AL drones \\
\hline Ascomycota sp. & Magnaporthales (A) & 99 & 95 & JQ692165 & 17 & 4 & 5 \\
\hline Cladosporium-complex & Capnodiales (A) & 100 & 100 & KP143685 & 17,520 & 377 & 6202 \\
\hline Fusarium polyphialidicum & Hypocreales (A) & 100 & 97 & HQ607880 & 16 & 3 & 67 \\
\hline Fusarium decemcellulare & Hypocreales (A) & 100 & 99 & KR534720 & 5 & 2 & 25 \\
\hline
\end{tabular}

A Ascomycota, $\mathrm{AC}=$ A. capiguara, $\mathrm{AL}=$ A. laevigata

Rarefaction analysis of the MOTUs showed that the asymptote was approached for all three samples (Fig. 1) suggesting that 454 pyrosequencing recovered most of the fungal species present on the integument of the sampled ants. The diversity index revealed that A. capiguara drones had the highest diversity (Fisher's alpha: 6.2) followed by A. laevigata drones (Fisher's alpha: 6.1).

From the 99 fungal taxa identified, $78.8 \%$ belonged to Ascomycota, $16.2 \%$ to Basidiomycota and $5 \%$ to Mucoromycotina. The orders Pleosporales, Capnodiales and Hypocreales encompassed the highest number of MOTUs for ascomycetous fungi (Fig. 2). Basidiomycetous fungi were mostly classified in the order Tremellales. On the other hand, Mucoromycotina is represented exclusively by the order Mucorales and encompasses only Cunninghamella and Mucor species. Also, $13.1 \%$ of the MOTUs represent uncultured fungi.

\section{Discussion}

Studies on the mycobiota present on the integument of leaf-cutting ants are relatively recent and only four studies are published on this subject (Pagnocca et al.
2008; Guedes et al. 2012; Arcuri et al. 2014; Duarte et al. 2014). The relationship of these cuticular fungi with ants is still unknown but Attili-Angelis et al. (2014) suggested that the presence of melanised fungi (order Chaetothyriales) may be favored by the hydrocarbon composition in the cuticle of these insects.

Although these works contributed to the knowledge of fungi present on the integument of attine ants, the sole use of culture-dependent techniques limited the study of fungal diversity and the finding of putative unknown species that fail to grow on artificial media. In this context, the present study evaluated the fungal diversity associated with the integument of alate leafcutting ants using pyrosequencing.

As expected, we found the mutualistic fungus on gynes of A. capiguara. L. gongylophorus was also found on drones of A. capiguara, even though in a lower number of reads. As the reproductive caste is raised in the parental fungus garden, the mutualistic fungal hyphae could be attached to the integument of gynes and drones, however L. gongylophorus was not detected on drones of A. laevigata. Besides that, because ant female alates carry mycelium pellets in internal infrabucal pockets (Autuori 1941) it is likely that our method to recover DNA from the integument 
Table 3 The ten top abundant MOTUs found in each sample based on closest match in NCBI database

\begin{tabular}{|c|c|c|c|c|c|c|c|}
\hline & Best hit at NCBI database & $\begin{array}{l}\text { Taxonomic } \\
\text { assignment }\end{array}$ & $\begin{array}{l}\text { Coverage } \\
(\%)\end{array}$ & $\begin{array}{l}\text { Similarity } \\
(\%)\end{array}$ & $\begin{array}{l}\text { Accession } \\
\#\end{array}$ & $\begin{array}{l}\text { No. of } \\
\text { reads }\end{array}$ & $\begin{array}{l}\% \\
\text { total }\end{array}$ \\
\hline \multirow{10}{*}{$\begin{array}{l}\text { A. capiguara } \\
\text { drones }\end{array}$} & Cladosporium-complex & Capnodiales (A) & 100 & 100 & GU395509 & 17,520 & 76.2 \\
\hline & Cryptococcus laurentii & Tremellales (B) & 81 & 98 & KP131909 & 2754 & 12 \\
\hline & Dothideomycetes sp. & Pleosporales (A) & 100 & 99 & KM519276 & 970 & 4.2 \\
\hline & Cunninghamella sp. & Mucorales (M) & 88 & 90 & KR812209 & 339 & 1.5 \\
\hline & Phoma draconis & Pleosporales (A) & 88 & 100 & KP276621 & 322 & 1.4 \\
\hline & Teratosphaeriaceae sp. 2 & Capnodiales (A) & 100 & 94 & KT833169 & 213 & 0.93 \\
\hline & Coniothyrium sp. & Pleosporales (A) & 87 & 98 & DQ092505 & 145 & 0.63 \\
\hline & Cunninghamella bainieri & Mucorales (M) & 99 & 93 & KF201293 & 145 & 0.63 \\
\hline & Periconia macrospinosa & Pleosporales (A) & 100 & 99 & JQ781723 & 66 & 0.29 \\
\hline & Pseudocercospora norchiensis & Capnodiales (A) & 100 & 100 & EF394859 & 52 & 0.23 \\
\hline \multirow{11}{*}{$\begin{array}{l}\text { A. capiguara } \\
\text { gynes }\end{array}$} & Cladosporium-complex & Capnodiales (A) & 99 & 99 & HQ608074 & 377 & 39.8 \\
\hline & Leucoagaricus gongylophorus & Agaricales (B) & 100 & 99 & KJ531208 & 351 & 37.5 \\
\hline & Teratosphaeriaceae sp. 4 & Capnodiales (A) & 100 & 99 & KT833162 & 58 & 6.1 \\
\hline & Fusarium oxysporum & Hypocreales (A) & 100 & 100 & KT794176 & 35 & 3.7 \\
\hline & Teratosphaeriaceae sp. 2 & Capnodiales (A) & 100 & 98 & KT833169 & 32 & 3.4 \\
\hline & Teratosphaeriaceae sp. 1 & Capnodiales (A) & 100 & 100 & KT833155 & 11 & 1.2 \\
\hline & Phanerochaete tuberculata & Polyporales (B) & 98 & 94 & AY219356 & 10 & 1.1 \\
\hline & Clonostachys byssicola & Hypocreales (A) & 100 & 100 & KC806270 & 6 & 0.63 \\
\hline & Uncultured fungus 4 & Pleosporales (A) & 100 & 99 & FJ213550 & 6 & 0.63 \\
\hline & Pseudocercospora fuligena & Capnodiales (A) & 100 & 88 & GU214675 & 5 & 0.53 \\
\hline & Trichosporon chiarellii & Tremellales (B) & 99 & 99 & GQ338074 & 5 & 0.53 \\
\hline \multirow{10}{*}{$\begin{array}{l}\text { A. laevigata } \\
\text { drones }\end{array}$} & Cladosporium-complex & Capnodiales (A) & 100 & 99 & GU395509 & 6202 & 53.5 \\
\hline & Epicoccum sp. & Pleosporales (A) & 100 & 99 & KR024724 & 3955 & 34 \\
\hline & Aureobasidium leucospermi & Dothideales (A) & 100 & 99 & JN712487 & 399 & 3.4 \\
\hline & Bionectria sp. & Hypocreales (A) & 100 & 99 & HM849058 & 111 & 0.96 \\
\hline & Teratosphaeriaceae sp. 3 & Capnodiales (A) & 98 & 97 & KT833168 & 107 & 0.92 \\
\hline & Fusarium incarnatum-equiseti complex & Hypocreales (A) & 100 & 100 & KJ562367 & 96 & 0.83 \\
\hline & Uncultured fungus 1 & Pleosporales (A) & 100 & 99 & GU053794 & 95 & 0.82 \\
\hline & Alternaria alternata & Pleosporales (A) & 100 & 100 & KU866390 & 74 & 0.64 \\
\hline & Fusarium polyphialidicum & Hypocreales (A) & 100 & 97 & HQ607880 & 67 & 0.58 \\
\hline & Trichosporon asahii & Tremellales (B) & 100 & 99 & KU095859 & 63 & 0.54 \\
\hline
\end{tabular}

A Ascomycota, $B$ Basidiomycota, $M$ Mucoromycotina

also extracted DNA from the mutualistic fungus present in the pellets.

Besides the ant mutualistic fungus, our results revealed a diverse fungal community associated with both ant species examined. Moreover, it has become more apparent that the ants' integument represents a microenvironment for several microorganisms that interact among themselves and may interfere in the complex attine ant-microbe interaction (Little and Currie 2007; Ishak et al. 2011).
As gynes are at least twice the size than drones (Online Resource 2), and for this reason they have a higher contact surface with surrounding environment, we expected a higher number of reads obtained from these insects; however, we observed that $A$. capiguara gynes had the lowest number of reads $(\mathrm{n}=934)$ and MOTUs $(\mathrm{n}=25)$. Using a culturedependent technique that favored the growth of melanised fungi, Duarte et al. (2014) isolated 17 fungal taxa from 100 A. capiguara gynes' 
(a) A. capiguara drones

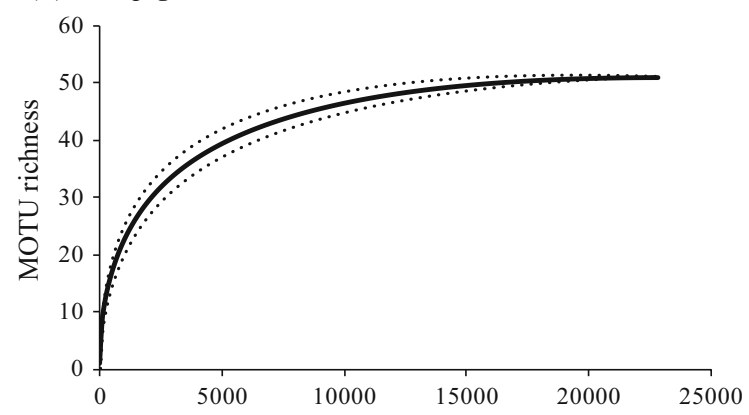

(b) A. capiguara gynes

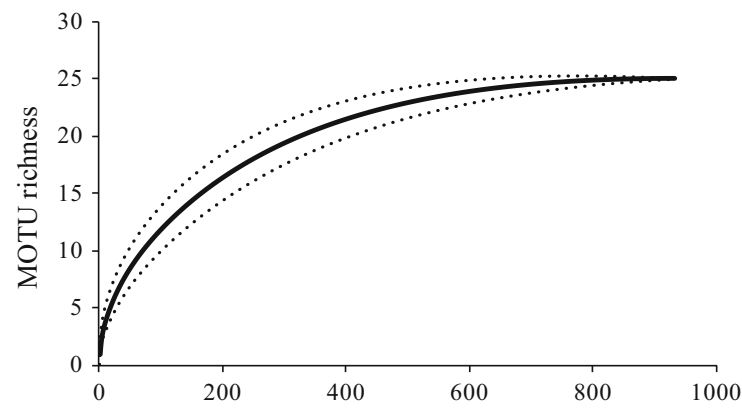

(c) A. laevigata drones

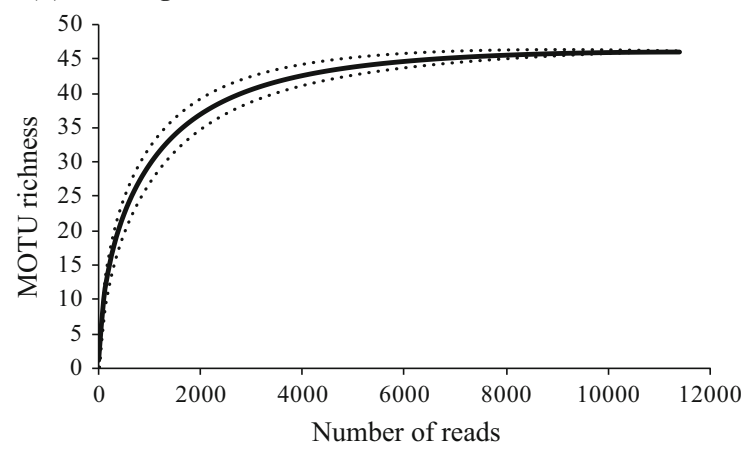

Fig. 1 Rarefaction curves (solid lines) of observed MOTU richness at $97 \%$ sequence similarity along with the $95 \%$ confidence intervals (dotted lines) on the integument of $A$. capiguara drones (a), A. capiguara gynes (b) and A. laevigata drones (c)

integuments, a lower fungal richness compared to the present study.

Fisher's alpha diversity index showed that drones of A. capiguara and A. laevigata had the highest fungal richness. In fact, these samples also exhibited the highest number of MOTUs (51 and 46, respectively). The study on the mycobiota associated with drones is recent and Arcuri et al. (2014) showed a wide diversity of yeasts on the integument of A. sexdens
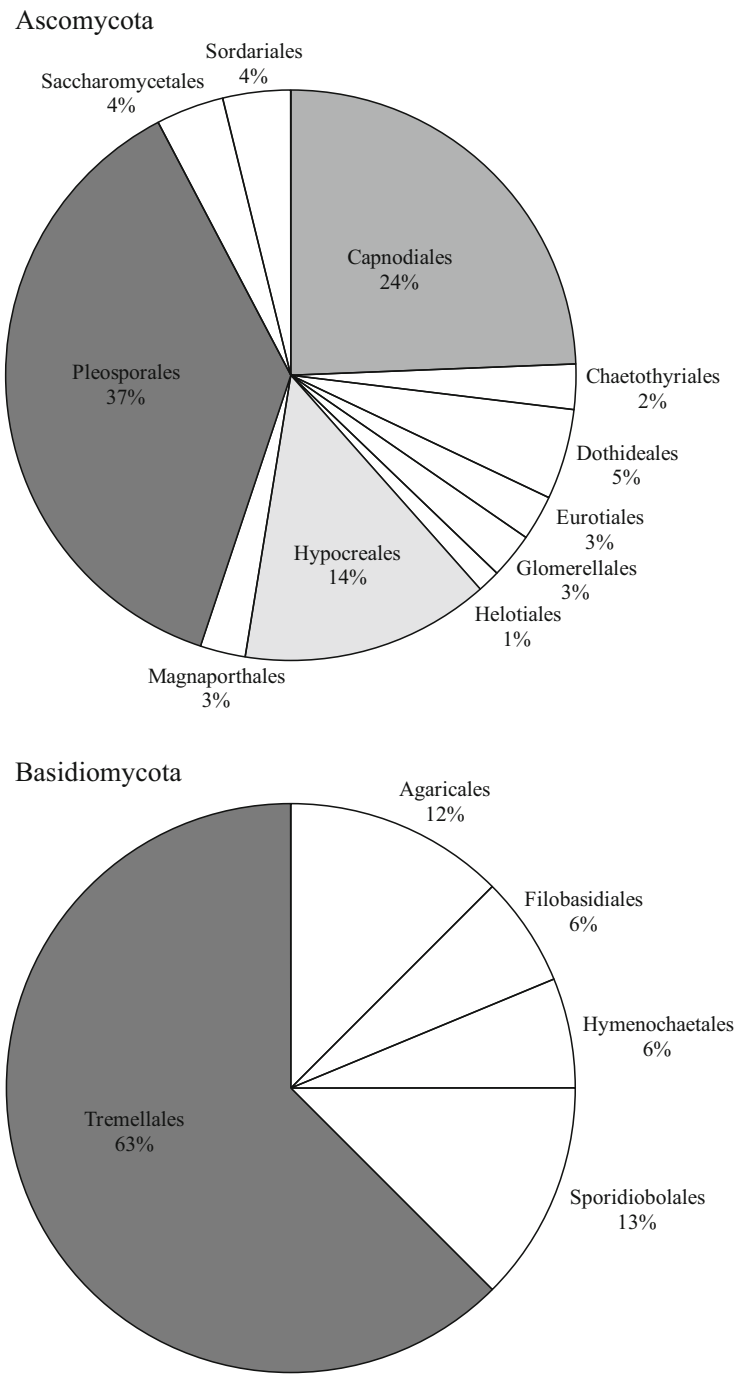

Fig. 2 Distribution of the 99 fungal MOTUs obtained from the integument of $A$. capiguara drones, A. capiguara gynes and $A$. laevigata drones, according to the phylogenetic assignment

rubropilosa drones, with predominance of Aureobasidium and Cryptococcus species.

According to the Jaccard and Sorensen's similarity indices, drones and gynes of A. capiguara are more similar to each other than to drones of A. laevigata regarding the fungal diversity. In addition, the number of shared MOTUs among the three samples was very low $(n=4)$. These results support the hypothesis of Duarte et al. (2014) that the fungal community associated with $A$. capiguara and A. laevigata alate ants are distinct. However, this conclusion should be carefully considered as it is based in a limited number of samples. 
The clustered MOTUs suggest that the fungal populations present on the integument of leaf-cutting ants belong to the phyla Ascomycota, Basiodiomycota and Mucoromycotina. The two ascomycetous orders with the highest number of MOTUs, Pleosporales and Capnodiales, comprise epiphytes, endophytes, saprobes and plant parasites (Crous et al. 2009; Zhang et al. 2012). Hypocreales was another ascomycetous order frequently obtained in this study and includes plant pathogens and biocontrol agents (Samuels et al. 2006). Thus, the most abundant orders comprise plantrelated fungi that may enter into the nests through different plants harvested by these leaf-cutting ants and, once incorporated in the fungus gardens, they can contaminate the integument of worker ants and alates as well.

Reads assigned to the genus Cladosporium (Capnodiales, Ascomycota) were prevalent in all samples and accounted for $67.9 \%$ of all reads obtained. Pagnocca et al. (2008) reported massive isolation of this genus from the integument of A. capiguara and $A$. laevigata gynes, suggesting that leaf-cutting ants may be an important carrier of Cladosporium species.

Species of Cladosporium are ubiquitous and, therefore, they are found in a wide range of environments (Bensch et al. 2012). Besides, Cladosporium is frequently isolated from soil (Domsch et al. 1980), air (O'Gorman and Fuller 2008) and is a common endophyte (Kumaresan and Suryanarayanan 2002) and plant pathogen (Thomma et al. 2005). Although their role in the attine symbiosis is unknown, the remarkable presence of Cladosporium in the integument of these ants suggests that this fungus is favored in this microenvironment and might use the ants as dispersal vehicle.

Contrary to the results obtained by Duarte et al. (2014), we found a lower diversity of chaetothyrialean fungi that could be explained by the small number of ants evaluated $(\mathrm{n}=30)$ as both studies sampled the same nests of alate ants species. The melanised fungi Cladophialophora, Ochroconis and Phialophora isolated by Duarte et al. (2014) were not observed in the pyrosequencing. Furthermore, Phialophora-related species, suggested to be symbiont of attine ants by Little and Currie (2007), were also not found.

From the Basidiomycota phylum, Cryptococcus laurentii (order Tremellales) was the most abundant taxon and observed only in A. capiguara drones. This basidiomycetous yeast has been shown to be prevalent in the attine ants microenvironment and it has been reported in the fungus garden (Middelhoven et al. 2003) and integument of gynes (Pagnocca et al. 2008) and drones (Arcuri et al. 2014). Mendes et al. (2012) showed that, besides $C$. laurentii, many other yeasts present in the fungus garden of leaf-cutting ants, are able to assimilate galacturonic acid, a compound derived from the hydrolysis of pectin (Siqueira et al. 1998) by Leucoagaricus and considered harmful to ants' survival.

Interestingly, Trichosporon chiarellii has been frequently reported in association with attine ants (Pagnocca et al. 2010) and so far was not found in another environment. Here, we found this yeast species on the integuments of A. capiguara gynes (five reads). Arcuri et al. (2014) isolated T. chiarellii from the integument of A. sexdens rubropilosa drones before the mating flight. Because alate ants might be responsible for the vertical transmission of some microorganisms, the present report supports the hypothesis that $T$. chiarellii could be an autochtonous species in attine ant colonies.

Thirteen MOTUs were identified as uncultured fungi but all were classified to at least the order level. These results show that members of the fungal community associated with the integument of leafcutting ants remain poorly described.

Our study indicates that the integument of leafcutting ant alates harbor a wide diversity of fungi and many have not been recovered by culture-dependent methods. The complex relationship among fungi and other associated organisms in this microenvironment has been insufficiently researched and may contain the fundamental key to elucidate the mechanisms used by the ant in nurturing the mutualistic fungus and defence against natural enemies.

Acknowledgments This study was supported by "Fundação de Amparo a Pesquisa do Estado de São Paulo" (FAPESPProc. 2013/08540-4) and CNPq (National Council for Scientific and Technological Development; Grant Number: 560.682/ 2010-7 and 448941/2014-7). Collections were conducted under collecting Permit Number 36333-1 issued by the "Instituto Brasileiro do Meio Ambiente e dos Recursos Naturais Renováveis" (IBAMA) and the "Instituto Chico Mendes de Conservação da Biodiversidade" (ICMBio).We also thank José Luiz Novelli, for allowing the ants collections in the Fazenda Santana, São Paulo State, Brazil.

\section{Compliance with ethical standards}

Conflict of interest The authors declare that they have no conflict of interest. 


\section{References}

Arcuri SL, Pagnocca FC, Melo WGP, Nagamoto NS, Komura DL, Rodrigues A (2014) Yeasts found on an ephemeral reproductive caste of the leaf-cutting ant Atta sexdens rubropilosa. Antonie Leeuwenhoek 106:475-487. doi:10. 1007/s10482-014-0216-2

Arfi Y, Buée M, Marchand C, Levasseur A, Record E (2012) Multiple markers pyrosequencing reveals highly diverse and host-specific fungal communities on the mangrove trees Avicennia marina and Rhizophora stylosa. FEMS Microbiol Ecol 79:433-444. doi:10.1111/j.1574-6941. 2011.01236.x

Attili-Angelis D, Duarte APM, Pagnocca FC, Nagamoto NS, de Vries M, Stielow JB, de Hoog GS (2014) Novel Phialophora species from leaf-cutting ants (tribe Attini). Fungal Divers 65:65-75. doi:10.1007/s13225-013-0275-0

Autuori M (1941) Contribuição para o conhecimento da saúva (Atta spp.). I. Evolução do sauveiro (Atta sexdens rubropilosa Forel, 1908). Arq Inst Biol São Paulo 12:197-228

Balajee SA, Houbraken J, Verweij PE, Hong S-B, Yaghuchi T, Varga J, Samson RA (2007) Aspergillus species identification in the clinical setting. Stud Mycol 59:39-46. doi:10. 3114/sim.2007.59.05

Bensch K, Braun U, Groenewald JZ, Crous PW (2012) The genus Cladosporium. Stud Mycol 72:1-401. doi:10.3114/ $\operatorname{sim} 0003$

Bensch K, Groenewald JZ, Braun U, Dijksterhuis J, YáñezMorales MJ, Crous PW (2015) Common but different: the expanding realm of Cladosporium. Stud Mycol 82:23-74. doi:10.1016/j.simyco.2015.10.001

Colwell RK, Chao A, Gotelli NJ, Lin S-Y, Mao CX, Chazdon RL, Longino JT (2012) Models and estimators linking individual-based and sample-based rarefaction, extrapolation, and comparison of assemblages. J Plant Ecol 5:3-21. doi:10.1093/jpe/rtr044

Crous PW, Schoch CL, Hyde KD, Wood AR, Gueidan C, de Hoog GS, Groenewald JZ (2009) Phylogenetic lineages in the Capnodiales. Stud Mycol 64:17-47. doi:10.3114/sim. 2009.64.02

Domsch KH, Gams W, Anderson T (1980) Compendium of soil fungi. Academic, London

Duarte APM, Attili-Angelis D, Baron NC, Forti LC, Pagnocca FC (2014) Leaf-cutting ants: an unexpected microenvironment holding human opportunistic black fungi. Antonie Leeuwenhoek 106(3):465-473. doi:10.1007/s10482-014-0215-3

Ewing B, Green P (1998) Base-calling of automated sequencer traces using phred. II. Error probabilities. Genome Res 8:186-194. doi:10.1101/gr.8.3.186

Ewing B, Hillier L, Wendl MC, Green P (1998) Base-calling of automated sequencer traces using phred. I. Accuracy assessment. Genome Res 8:175-185. doi:10.1101/gr.8.3.175

Ferro M, Antonio EA, Souza W, Bacci M (2014) ITScan: a webbased analysis tool for Internal Transcribed Spacer (ITS) sequences. BMC Res Notes 7:857. doi:10.1186/17560500-7-857

Folgarait P, Gorosito N, Poulsen M, Currie CR (2011) Preliminary in vitro insights into the use of natural fungal pathogens of leaf-cutting ants as biocontrol agents. Curr Microbiol 63(3):250-258. doi:10.1007/s00284-011-9944-y
Gillevet PM, Sikaroodi M, Torzilli AP (2009) Analyzing saltmarsh fungal diversity: comparing ARISA fingerprinting with clone sequencing and pyrosequencing. Fungal Ecol 2(4):160-167. doi:10.1016/j.funeco.2009.04.001

Guedes FLA, Attili-Angelis D, Pagnocca FC (2012) Selective isolation of dematiaceous fungi from the workers of Atta laevigata (Formicidae: attini). Folia Microbiol 57:21-26. doi:10.1007/s12223-011-0081-6

Ishak HD, Miller JL, Sen R, Dowd SE, Meyer E, Mueller UG (2011) Microbiomes of ant castes implicate new microbial roles in the fungus-growing ant Trachymyrmex septentrionalis. Sci Reports 1:204. doi:10.1038/srep00204

Katoh K, Standley DM (2013) MAFFT Multiple Sequence Alignment Software Version 7: improvements in performance and usability. Mol Biol Evol 30(4):772-780. doi:10. 1093/molbev/mst010

Kumaresan V, Suryanarayanan TS (2002) Endophyte assemblage in young, mature and senescent leaves of Rhizophora apiculata: evidence for the role of endophytes in mangrove litter degeneration. Fungal Divers 9:81-91

Lentendu G, Zinger L, Manel S, Coissac E, Choler P, Geremia RA, Melo de Lima C (2011) Assessment of soil fungal diversity in different alpine tundra habitats by means of pyrosequencing. Fungal Divers 49(1):113-123. doi:10. 1007/s13225-011-0101-5

Lim YW, Kim BK, Kim C, Jung HS, Kim B-S, Lee J-H, Chun J (2010) Assessment of soil fungal communities using pyrosequencing. J Microbiol 48(3):284-289. doi:10.1007/ s12275-010-9369-5

Little AE, Currie CR (2007) Symbiotic complexity: discovery of a fifth symbiont in the attine-microbe symbiosis. Biol Lett 3:501-504. doi:10.1098/rsbl.2007.0253

Lopez E, Orduz S (2003) Metarhizium anisopliae and Trichoderma viride for control of nests of the fungus-growing ant, Atta cephalotes. Biol Control 27:194-200. doi:10.1016/ S1049-9644(03)00005-7

Loro M, Valero-Jiménez CA, Nozawa S, Márquez LM (2012) Diversity and composition of fungal endophytes in semiarid Northwest Venezuela. J Arid Environ 85:46-55. doi:10.1016/j.jaridenv.2012.04.009

Lumini E, Orgiazzi A, Borriello R, Bonfante P, Bianciotto V (2010) Disclosing arbuscular mycorrhizal fungal biodiversity in soil through a land-use gradient using a pyrosequencing approach. Environ Microbiol 12(8):2165-2179. doi:10.1111/j.1462-2920.2009.02099.x

Mendes TD, Rodrigues A, Dayo-Owoyemi I, Marson FAL, Pagnocca FC (2012) Generation of nutrients and detoxification: possible roles of yeasts in leaf-cutting ant nests. Insects 3:228-245. doi:10.3390/insects3010228

Middelhoven WJ, Fonseca A, Carreiro SC, Pagnocca FC, Bueno OC (2003) Cryptococcus haglerorum sp. nov., an anamorphic basidiomycetous yeast isolated from nests of the leaf-cutting ant Atta sexdens. Antonie van Leeuwenhoek 83:167-174. doi:10.1023/A:1023384830802

Montoya QV, Meirelles LA, Chaverri P, Rodrigues A (2016) Unraveling Trichoderma species in the attine ant environment: description of three new taxa. Antonie van Leeuwenhoek 109(5):633-651. doi:10.1007/s10482-016-0666-9

Mueller UG (2012) Symbiont recruitment versus ant-symbiont co-evolution in the attine ant-microbe symbiosis. Curr 
Opin Microbiol 15(3):269-277. doi:10.1016/j.mib.2012. 03.001

Nilsson RH, Abarenkov K, Veldre V, Nylinder S, De Wit P, Brosché S, Alfredsson JF, Ryberg M, Kristiansson E (2010) An open source chimera checker for the fungal ITS region. Mol Ecol Resour 10:1076-1081. doi:10.1111/j. 1755-0998.2010.02850.x

O'Gorman CM, Fuller HT (2008) Prevalence of culturable airborne spores of selected allergenic and pathogenic fungi in outdoor air. Atmos Environ 42:4355-4368. doi:10.1016/j. atmosenv.2008.01.009

Ortiz A, Orduz S (2000) In vitro evaluation of Trichoderma and Gliocladium antagonism against symbiotic fungus of the leaf-cutting ant Atta cephalotes. Mycopathologia 150:53-60. doi:10.1023/A:1010843413085

Pagnocca FC, Rodrigues A, Nagamoto NS, Bacci M Jr (2008) Yeasts and filamentous fungi carried by the gynes of leafcutting ants. Antonie Leeuwenhoek 94:517-526. doi:10. 1007/s10482-008-9268-5

Pagnocca FC, Legaspe MFC, Rodrigues A, Ruivo CCC, Nagamoto NS, Bacci M Jr, Forti LC (2010) Yeasts isolated from a fungus-growing ant nest, including the description of Trichosporon chiarellii sp. nov., an anamorphic basidiomycetous yeast. Int J Syst Evol Microbiol 60:1454-1459. doi:10.1099/ijs.0.015727-0

Reis BMS, Silva A, Alvarez MR, Oliveira TB, Rodrigues A (2015) Fungal communities in gardens of the leafcutter ant Atta cephalotes in forest and cabruca agrosystems of southern Bahia State (Brazil). Fungal Biol 119:1170-1178. doi:10.1016/j.funbio.2015.09.001

Robert V, Vu D, Amor ABH et al (2013) MycoBank gearing up for new horizons. IMA Fungus 4(2):371-379

Rodrigues A, Passarini MRZ, Ferro M, Nagamoto NS, Forti LC, Bacci M Jr, Sette LD, Pagnocca FC (2014) Fungal communities in the garden chamber soils of leaf-cutting ants. J Basic Microbiol 54(11):1186. doi:10.1002/jobm. 201200458

Samuels GJ, Rossman AY, Chaverri P, Overton BE, Põldmaa K (2006) Hypocreales of the Southeastern United States: an identification guide. Utrecht, Netherlands

Schloss PD, Westcott SL, Ryabin T, Hall JR, Hartmann M, Hollister EB, Lesniewski RA, Oakley BB, Parks DH, Robinson CJ, Sah JW, Stres B, Thallinger GG, Van Horn DJ, Weber CF (2009) Introducing mothur: open-source, platform-independent, community-supported software for describing and comparing microbial communities. Appl
Environ Microbiol 75(23):7537-7541. doi:10.1128/AEM. 01541-09

Schmieder R, Edwards R (2011) Quality control and preprocessing of metagenomic datasets. Bioinformatics 27:863-864. doi:10.1093/bioinformatics/btr026

Schultz TR, Brady SG (2008) Major evolutionary transitions in ant agriculture. Proc Natl Acad Sci 105:5435-5440. doi:10. 1073/pnas.0711024105

Silva A, Bacci M Jr, Siqueira CG, Bueno OC, Pagnocca FC, Hebling MJA (2003) Survival of Atta sexdens workers on different food sources. J Insect Physiol 49(4):307-313. doi:10.1016/S0022-1910(03)00004-0

Siqueira CG, Bacci M Jr, Pagnocca FC, Bueno OC, Hebling MJA (1998) Metabolism of plant polysaccharides by Leucoagaricus gongylophorus, the symbiotic fungus of the leaf-cutting ant Atta sexdens. L Appl Environ Microbiol 64:4820-4822

Tamura K, Stecher G, Peterson D, Filipski A, Kumar S (2013) MEGA6: Molecular Evolutionary Genetics Analysis Version 6.0. Mol Biol Evol 30:2725-2729. doi:10.1093/ molbev/mst 197

Tedersoo L, Nilsson RH, Abarenkov K, Jairus T, Sadam A, Saar I, Bahram M, Bechem E, Chuyong G, Kõljalg U (2010) 454 Pyrosequencing and Sanger sequencing of tropical mycorrhiza fungi provide similar results but reveal substantial methodological biases. New Phytol 188:291-301. doi:10. 1111/j.1469-8137.2010.03373.x

Thomma BPHJ, Van Esse HP, Crous PW, De Wit PJGM (2005) Cladosporium fulvum (syn. Passalora fulva), a highly specialized plant pathogen as a model for functional studies on plant pathogenic Mycosphaerellaceae. Mol Plant Pathol 6(4):379-393. doi:10.1111/J.1364-3703.2005.00292.X

Visagie CM, Houbraken J, Frisvad JC, Hong S-B, Klaasen CHW, Perrone G, Seifert KA, Varga J, Yaguchi T, Samson RA (2014) Identification and nomenclature of the genus Penicillium. Stud Mycol 78:343-371. doi:10.1016/j. simyco.2014.09.001

Weber NA (1972) The fungus-culturing behavior of ants. Am Zool 12:577-587

White TJ, Bruns T, Lee S, Taylor J (1990) Amplification and direct sequencing of fungal ribosomal RNA genes for phylogenetics. In: Innis MA, White T, Sninsky JJ (eds) PCR protocols: a guide to methods and applications. Academic Press, San Diego

Zhang Y, Crous PW, Schoch CL, Hyde KD (2012) Pleosporales. Fungal Divers 53:1-221. doi:10.1007/s13225-011-0117-x 